sciendo

\title{
Spontaneous Linguistic Understanding: a few Introductory Remarks
}

\author{
André Leclerc \\ Federal University of Ceará-Fortaleza
}

Disputatio Vol. 4, No. 34

December 2012

DOI: $10.2478 /$ disp-2012-0029

ISSN: 0873-626X 


\title{
Spontaneous Linguistic Understanding: a few Introductory Remarks
}

\author{
André Leclerc \\ Federal University of Ceará-Fortaleza \\ BIBLID [0873-626X (2012) 34; pp. 713-737]
}

Let me try to explain from the outset what I mean by "spontaneous linguistic understanding" (SLU). As a first approximation, it is the non-reflexive, fluent, direct and mostly non-inferential process by which a speaker-hearer dynamically, by considering usually stretches of discourse rather than isolated sentences, determines the intuitive truth conditions (or, in general, the satisfaction conditions) of the $u t-$ terances performed in a specific context of use. Most people on Earth enjoy that kind of experience all the time in their mother tongue. The view of SLU I shall try to develop here takes actions and plans as a starting point, that is, utterances usually performed as part of bigger plans. Rarely do we perform isolated actions; our actions, as a rule, are parts of plans, steps towards the achievement of a project. This, of course, holds for sequences of speech acts in a discourse or conversation. As there are always different ways to perform the same act-type, it is no surprise that there may be different ways to perform any speech act-type. ${ }^{1}$ Utterances are actions, and SLU, as we shall see, is tied to occurrent understanding of utterances. SLU is also a dynamic process that considers a topic that can be developed in different ways. However, it is obvious that what has been said in a discourse or a conversation smoothly restricts what can be relevantly said soon afterwards. In this process, truth conditions are grasped, especially those actually grasped and considered by the

${ }^{1}$ An act-type is denoted by an infinitive verb or a gerund; speech acts types denoted by illocutionary verbs share the same property: their performances vary and produce slightly, but meaningful different effects usually perceived by the hearers.

Disputatio, Vol. IV, No. 34, December 2012 
agents of the context (intuitive truth conditions), and not those that derive only from the knowledge of the general conventions and rules of language. ${ }^{2}$

Perhaps, the best way to delimitate the foregoing concept is to contrast what it represents, first, with "interpretation" (by that I mean hermeneutic practices, the most common and the most sophisticated as well), clearly a reflexive and inferential activity, and second, with cases of communication when one does not master completely the language of the addressee. Then I present the distinction dispositional/occurrent understanding and two famous philosophical programs: I see Davidson's program as a hypothesis about the structure of dispositional understanding, while Gricean program provide an interesting view about utterance (occurrent) understanding. I show that both programs are inadequate. I close the paper with a few suggestions on the status of semantic knowledge, on the immediate object of SLU, and an attempt to defend the conjecture that spontaneous linguistic understanding is grounded on the more basic understanding of actions and situations.

\section{A preliminary delimitation of the concept}

\section{A) Some historical milestones}

As usual in contemporary philosophy, the idea is not radically new. SLU was a great concern in the tradition of ideational theory of language, especially as developed by the most important proponent of that classical approach in the XVIIth century: Antoine Arnauld. He established such a contrast between the way most people, most of the time, understand utterances and judge the meaning of words, and the work done by hermeneutists. This way of judging spontaneously the meanings of words he called "sentiment," something comparable to Chomsky's speaker intuition, but not limited to syntax. It is, he said, the most universal and common way of judging almost everything. It is also "the surest, the finest, and the subtlest."

\footnotetext{
${ }^{2}$ On intuitive truth conditions, see François Recanati, Truth-conditional Pragmatics, Oxford, O.U.P., 2010; also his Literal Meaning, Cambridge, C.U.P., 2004.
} 
This is the way human beings assess almost all the variety of things in the world. We recognize at once that two very resembling persons are nonetheless different, without paying attention to details, to what is in the face of one that is not in the face of the other. The impression marks all this in the mind, without revealing distinctly the particular differences. ${ }^{3}$

Arnauld believed that this is the usual form of judgment we apply when we judge instantaneously (or "feel") that two words with very similar meanings have nonetheless different senses or conditions of application. The sentiment is a basic discriminatory capacity; applied to semantics, it allows us to discern "at once the finest differences between expressions better than all the rules in the world." The mind just "feels" differences that cannot be made explicit without difficulty. In these cases, as Michael Polanyi nicely once put it, "we can know more that we can tell". Interestingly, Arnauld says that "the rules themselves are true only whenever they conform to the sentiment."

Spontaneous understanding is the basis or starting point of any hermeneutic work. Arnauld contrasted this "sentiment" with the pigheadedness of some hermeneutists (invariably his enemies, the Protestants) who searched for hidden senses, sometimes a bit recherché, behind the words pronounced by ordinary people in ordinary circumstances. For Arnauld \& Nicole, to talk is to excite intentionally ideas in the mind of the hearer, or to cause intentionally a global impression in the mind of the hearer, and that impression is usually composed of ideas articulated in the sentence used, ideas inferred from the clues given by the speaker, and ideas neither articulated nor inferred (mimics, tone of voice, expressive character of gaze, etc.). So there is a clear distinction between the immediate understandings of utterances, that is, the global and complex impression received in a context of use, and the result of a discussion about what we should

${ }^{3}$ Antoine Arnauld \& Pierre Nicole, [1669-1672], La Grande Perpétuité de la foi de l'Eglise catholique sur l'Eucharistie, [G.P.], publiée par l'Abbé M***, Paris, Imprimerie de Migne, chez l'éditeur rue d'Amboise, Hors la barrière d'Enfer, 1841, Vol. 2, Book 1, p. 990. My translation. See also my paper (Leclerc, 2005). M. Polanyi, The Tacit Dimension, Chicago, The University of Chicago Press, 1966/2009, first chapter, "Tacit knowing”, where Polanyi made very similar remarks.

${ }^{4}$ Ibid, Vol. 2, Book II, chap. 1, p.122. 
understand in the same context.

More recently, Wittgenstein changed the focus in his own work from the theory of meaning to the theory of understanding, and discussed at some length "immediate understanding" (unmittelbar Verstehen), from the Big Typescript until the end of his life. As we know, linguistic understanding became a main concern in Wittgenstein's last philosophy. In contrast, the Tractatus does not pay much attention to linguistic understanding, with the notable exception of T.4.024, which establishes for the first time an analytic connection between the notion of linguistic understanding and that of truth-conditions. In the Philosophical Investigations, Wittgenstein strives to show that understanding is not a state, an event, a process or an experience. As a matter of fact, there is no single experience (or state, process, etc.) to which linguistic understanding can be reduced. This is not to say that there are no experiences at all involved in the understanding of a sentence or an utterance. Michael Dummett insisted, rightly, that "we need an occurrent sense of 'understand'..." Otherwise, the understanding of an utterance would be quite mysterious.

Still more recently, Burge drew a distinction between "comprehension" and "interpretation," the first being basically non-reflexive and non-inferential:

Comprehension is understanding that is epistemically immediate, unreasoned, and non-inferential. First-person comprehension is the minimal understanding presupposed in any thinking, in beings that understand their thoughts at all.

[...] I include words, in a derivative sense, as things one can comprehend in the first-person way. One comprehends the words in one's idiolect as one uses them. The comprehended words are the direct expression of thoughts one comprehends. They express one's thoughts without mediation of further words or thoughts.

[...] Interpretation arises out of there being a question or issue about how to understand a candidate object of interpretation. Interpretation is always from the third person point of view. I conjecture that it is

${ }^{5}$ Dummett, M. (1993). Origins of Analytical Philosophy. Cambridge (MA), Harvard University Press, p. 60; also on p. 103. For a discussion, see Guy Longworth, "A Plea for Understanding", in S. Sawyer (ed.), New Waves in the Philosophy of Language. Aldershot: Ashgate, 2009. 
always epistemically inferential. ${ }^{6}$

Interpretation is needed when something strange or surprising comes out, when there is a conflict or a disagreement as to the meaning of a sentence or of a stretch of a discourse. Interestingly, according to Burge, the first instance of understanding is the understanding of our own thoughts, and they are understood, mainly, in a non-inferential way. Of course, there are exceptions. After all, sometimes, people get confused; they don't know exactly what they want, for instance. And there can be degrees of understanding, or an incomplete grasping of a proposition. One may discover that one's belief that $\mathrm{P}$ has some unexpected presupposition or consequences. This corresponds to a deepening of our understanding. Thoughts readily expressible by linguistic means (full-fledged thoughts) and expressed by others are understood immediately when there is no need to interpret them.

\section{B) Linguistic understanding in a language not fully mas- tered}

Now suppose you are a tourist visiting a country speaking a language you do not master very well. Setting aside segmentation problems, you can understand, at least on some occasions, what the natives mean, but the understanding of what they say exactly is a painful and frustrating process. You have to pay attention constantly at every word in every sentence; you have the impression that the natives speak very fast all the time; and to form a less than secure interpretation of an utterance, you have to make a lot of inferences based on analytical hypotheses - to fill the gaps for the words you do not know yet - and on contextual clues. At night, you're back to the hotel, usually with a headache. After a few weeks, you return to your homeland and speak with the members of your family. Here is the contrast: At home, you enjoy fluent, effortless experiences of linguistic understanding. Very much like perception, these experiences are almost passive. You continuously get an "automatic," fast and direct access to intuitive satisfaction conditions for any sentence

${ }^{6}$ Tyler Burge, “Comprehension and Interpretation”, in L.E. Hahn (ed.): The Philosophy of Donald Davidson. Chicago and La Salle, Open Court, 1999, 236-237. 
of any syntactic type. This is what I call "spontaneous linguistic understanding."

\section{Semantic knowledge}

The analytic tradition has it that the understanding of a sentence is a kind of knowledge (knowledge of truth-conditions or satisfaction conditions). ${ }^{7}$ However, if that knowledge is propositional knowledge, we can raise serious doubts on that traditional tenet. Is understanding a kind of knowledge at all? Some epistemological issues here are unavoidable. ${ }^{8}$ I believe there are experiences of understanding, even if these experiences are semantically irrelevant to determine the meaning of the word "understanding," or even if none of these experiences could be correlated with something called "understanding." They are epistemologically important in order to distinguish linguistic understanding from the mere knowledge of the content of an utterance (What Is Said), and I believe they play an important role in the epistemology of testimony. SLU can be compare to perception on that score. I am allowed to testify in a court because I saw the murderer shooting the victim at midday, at an appropriate distance with my perfect vision, etc. In the same way, I am allowed to testify that, next door at the hotel, I heard a male voice in a tone of menace saying "I'm gonna kill you, bitch!" and then a female voice screaming "Help!". When the judge ask me, "Are you sure you heard just these words?" I can answer something like: "Well, the walls of the hotel are thin, the sounds was pretty distinct, and the accused speaks my mother tongue." The experience of hearing the sounds and the experience of direct discourse recognition enable me to testify. The knowledge of what has been said (the content of an utterance) can also be obtained through a reliable translation, but understanding requires the autonomous exercise of conceptual abilities, the use of our own semantic knowledge. So the kind of autonomous direct

${ }^{7}$ This has been challenged recently. See, Dean Pettit (2002), "Why Knowledge is Unnecessary for Understanding Language”, Mind, Vol. 111, n. 443, July 2002, 519-550.

${ }^{8}$ Understanding is one of the main topics in the Epistemology of Language. See Alex Barber (ed.) (2003), Epistemology of Language, Oxford, O.U.P., 2003. 
access to content that characterizes understanding (in contrast with indirect access through translation) presupposes at least these experiences.

If understanding is knowledge at all, what kind of knowledge is this? The Epistemic View takes understanding to be propositional knowledge of meaning. There are two steps leading to that conclusion. ${ }^{9}$

1. A understands $\mathrm{S}$ iff A knows what $\mathrm{S}$ means;

2. A knows what $\mathrm{S}$ means iff $\mathrm{A}$ knows that $\mathrm{S}$ means $m$.

$\therefore \quad$ A understands $\mathrm{S}$ iff $\mathrm{A}$ knows that $\mathrm{S}$ means $m .{ }^{10}$

Step 2 is highly questionable. According to the Epistemic View, knowledge of meaning is always propositional knowledge. If propositional knowledge of meaning is analyzed in terms of true justified belief (or any variation on that classical analysis, that is, one that involves a belief), we should ask what kind of belief is that? The basic axioms of a Davidsonian T-Theory do not qualify to be the content of a genuine belief. Disquotational axioms like

I. "Piaf" refers to Piaf;

II. "Ella" refers to Ella;

or a compositional axiom of the form

III. "a is more famous than b" is true iff the denotation of "a" is more famous than the denotation of "b",

are not suited to be the content of a genuine belief, as Gareth Evans showed convincingly. A genuine belief can serve different projects. If I believe that the water in the bottle on my desk has been poisoned (Evans' example), I can do different things on the basis of that belief: committing suicide, killing someone by offering the water or by preparing a drink with that water, pouring the content of the

\footnotetext{
${ }^{9}$ See Dean Pettit (2002).

10 "A" stands for any agent of the context; "S" for any expression or sentence; and " $m$ " for the meaning of $S$.
} 
bottle into the sink in order to prevent a tragedy, calling the police for investigating the case, etc. But what can I do with the belief that, say, "Lisbon" refers to Lisbon? "If the basic axioms of a T-Theory à la Davidson do not qualify as content for genuine belief, and if belief is a necessary ingredient in any analysis of propositional knowledge, then it seems that semantic knowledge cannot be propositional knowledge. Therefore, knowing what $\mathrm{S}$ means is not the same as knowing that $\mathrm{S}$ means $m$ (where $m$ can be a proposition, a concept, an idea, a function, a rule or an object).

Furthermore, propositional knowledge is "gettierable," that is, it fails in Gettier cases. When a justified belief represents a contingenthistorical fact, it is always possible to devise a case à la Gettier for the corresponding knowledge. But this does not work for linguistic understanding. Suppose that knowledge of meaning is propositional knowledge. Imagine you just immigrate in Brazil and start learning Portuguese with a closed group of friendly people. After a while, you talk good Portuguese fluently with these people. But they have enemies and these nasty, mischievous enemies of your new friends convince you, in English, that the Portuguese the friendly people taught you is all wrong; worst, they used false evidences that your friends misled you intentionally on most linguistic matters relative to Portuguese. Furious, you leave the community (the friendly people) believing that they played a trick on you and that you have good reasons not to thrust what you have "learned" with them. You now believe you haven't learned good Portuguese and you decided to start over learning by yourself in the street. Surprisingly, however, you have the impression that you understand perfectly what any pedestrian you encounter randomly tells you; moreover, their behavior confirms your understanding. In such a predicament, it seems that firm propositional knowledge is not necessary for understanding. The impression that you are understanding already counts as understanding. Here is one of Pettit conclusions:

I went on to argue that understanding language does not even require belief. That is, to understand a bit of language with a certain meaning,

\footnotetext{
${ }^{11}$ Gareth Evans, "Semantic Theory and Tacit Knowledge", in S. Holtzmann \& C. Leich (eds.) Wittgenstein: To Follow a Rule, London, Routledge, 1981. Also in G. Evans, Collected Papers, Oxford, Clarendon Press, 1985/2002, 322-342.
} 
it is not necessary even to believe that it has that meaning. It is sufficient, I have argued, that it seem to you to have that meaning, whether you believe it or not. ${ }^{12}$

There is some resemblance between Pettit's conclusion and the sentiment described by Arnauld \& Nicole, that spontaneous judgment on meaning on which the rules are based. Be that as it may, it is commonsensical that we know what we have learned (and not forgotten), and that natural languages are among the things we must learn. It is also obvious that in order to be able to understand a language, we must possess encyclopedic knowledge about the world, about the natural and social regularities. Linguistic conventions are social regularities. As it is hard to characterize satisfactorily the semantic knowledge needed to talk and understand normally a language, I shall adopt, for the time being, a very modest approach. I shall avoid any intellectualistic view, including the epistemic view, and make the following, naïve presupposition: SLU presupposes a huge set of dispositions, some enabling discourse recognition, while others, activated simultaneously, determine the contribution of sub-sentencial parts to the satisfaction conditions of illocutions of any type. By doing this, I just follow uncompromisingly Evans' suggestion:

I suggest that we construe the claim that someone tacitly knows a theory of meaning as ascribing to that person a set of dispositions - one corresponding to each of the expressions for which the theory provides a distinct axiom. ${ }^{13}$

I think, however, that we must associate two dispositions to each expression. It is possible to recognize the token of a word as being the token of a type without knowing its meaning. Of course, Evans was interested only in semantic knowledge, but for those interested in SLU, discourse recognition is fundamental. The theory of meaning he has in mind is one that adopts the format advocated by Davidson in "Truth and Meaning" (1967), with basic axioms for each expression, singular terms and predicates as well, from which are derived theorems (the famous "T-sentences") displaying the truth-conditions for each declarative sentence of the language. Interestingly, Davidson himself recognized that when he was speaking of "the theory a hear-

\footnotetext{
${ }^{12}$ Pettit, op. cit., 548.

${ }^{13}$ G. Evans, op. cit., p. 328.
} 
er has when he understands a speaker", this was a mere façon de parler.

[...] I do not speak of implicit knowledge here or elsewhere: the point is not that speaker or hearer has a theory, but that they speak and understand in accord with a theory - a theory that is needed only when we want to describe their abilities and performance. ${ }^{14}$

That amounts to a kind of instrumentalism in theory of meaning. This is wise and prudent. But I think more can be said about the structure of dispositional understanding. I now turn to the distinction introduced by Michael Dummett between dispositional understanding and occurrent understanding. I shall defend that dispositional understanding must be relatively stable, while occurrent understanding is context-sensitive. ${ }^{15}$

\section{Dispositional and occurrent understanding}

While the theory of meaning has always been a main concern in analytic philosophy, the theory of linguistic understanding, strangely enough, did not receive the same attention. But we already have at our disposal a few useful distinctions, and two important philosophical programs to start with.

As a first step, we have to distinguish two basic kinds of linguistic understanding. Firstly, the "occurrent understanding" of utterances; in that case what we understand is what the speaker means in the context of utterance. The understanding of utterances is not only the understanding of sentences-token; it is also and more basically the understanding of actions performed for such and such a primary reason in a highly specific context. Secondly, we also have a "dispositional understanding" of sentences, expressions, bits of language; in that case, we understand what sentences mean, and they mean what they do in virtue of conventions, that is, social regularities of a certain type. The first kind of understanding clearly depends on the second kind of understanding. Quick occurrent understanding presupposes the existence of a huge set of dispositions acquired along

${ }^{14}$ D. Davidson, “The Social Aspects of Language", in Truth, Language and History, Oxford, Clarendon Press, 2005, p.113.

${ }^{15}$ For the distinction, see Michael Dummett, Origins of Analytical Philosophy, op. cit. 
the first years of a child's life (in the case of a mother tongue). Segmentation and discourse recognition would be impossible without this set of dispositions. This set represents the knowledge we have of a language (at least of our idiolect), that is, the abilities to speak and understand, to write and read. ${ }^{16}$ Basically, this is the knowledge of sound patterns (phonological knowledge) and the knowledge of what these sound patterns are regularly used to mean (semantic knowledge). Consequently, our concept of spontaneous linguistic understanding is tied to that of occurrent understanding. Dispositional understanding is not "spontaneous". Occurrent understanding is the autonomous exercise of an ability that always takes place in a specific context of utterance.

Dispositional understanding (the understanding of language or bits of language) is the tacit knowledge of the sound pattern and meaning an expression has as a type. It is the knowledge a competent speaker-hearer brings with him/her in any new context of utterance. There is an answer by "yes," "no," or "a little" to questions like: Do you know Japanese? Do you know Javanese? Do you know Spanish? By answering "yes," you are saying that you got through a process of learning, that you acquired and now possess a big set of dispositions that enables you to associate "automatically" senses to the characteristic sounds of a language. I think Austin's concept of descriptive conventions is quite useful here. A descriptive convention correlates a word (a categorem) to kinds of things (objects, states of affairs, situations). Lexical meaning in natural language is specified by a "descriptive convention". What we call "meaning," in this sense, is abstracted from social regularities. But the descriptive conventions only specify kinds of objects, kinds of situations and states of affairs or facts. Take the word "coffee". There is no such thing as "coffee-in-general". The descriptive convention for "coffee" must include, mainly, coffee beans, coffee powder, and coffee in a liquid state. Lexicographers have the choice between writing many different dictionary entries for the same word (a bad choice), or just a few

\footnotetext{
${ }^{16}$ For an interesting suggestion as to the structure and working of these dispositions, see Gareth Evans, "Semantic Theory and Tacit Knowledge", op. cit. For critiques and discussion of Evans' ideas, see also Crispin Wright, "Theories of Meaning and Speakers' Knowledge”, in Realism, Meaning and Truth. Oxford: Blackwell, 1993, 204-238.
} 
entries, indicating how different meanings derive from a main "core meaning." The second way of doing lexicography is certainly recommendable. It follows Grice's Razor in semantics: Do not multiply meanings beyond necessity, and keep semantics as simple as possible! For the word "coffee," when it is used to refer to the color, this use is clearly derived, and the same holds for "a coffee" (a cup of coffee), a kind of metonymy. The "core meaning" first described in a dictionary is something like "the seeds of a tropical bush from which, once roasted and crushed, a black, bitter and stimulating drink is made by adding hot water". Sometimes the stress is on the drink and not the seeds, but the whole information must be there. Determined by what Austin called "demonstrative conventions" (that correlate words and sentences to historical, real, specific objects and situations), related but slightly different semantic values are derived in context when "coffee," for instance, is used in an utterance to refer to coffee in a specific state (fresh coffee, old bitter coffee, coffee beans, etc.).

Tacit knowledge of meaning is what feeds the experiences of understanding, but it is not itself an experience, at least not in the same sense as sensations, perceptions, emotions, imaginations or memories are said to be experiences (or parts of experiences). Tacit knowledge of a meaning is a disposition. These "automatic" sound-sense associations are practically independent of the will, like perception. As George Lakoff points out, it is impossible to follow the command: "Don't think of an elephant!" ${ }^{17}$ When we hear the word "elephant" we cannot help but thinking of an elephant, of a large animal with floppy ears and a trunk. We do not choose the meaning of the words we understand as we do not choose to see what we see when we open our eyes. Of course, there are exceptions, "local agreements" on meanings and stipulative definitions, but it is obvious that we cannot do that massively and all the time. So, descriptive conventions, the object of dispositional understanding, must be relatively stable. Otherwise, it would be possible for everyone to develop something like a private language, so that, at the end of the day, our idiolects would be too divergent for the sake of communication.

Are there dispositional understandings of tokens produced on an

${ }^{17}$ See George Lakoff, Don't Think of an Elephant! White River Junction (Vermont), Chelsea Green Publishing, 2004. 
occasion? Well, suppose you open a text book of Basic English Grammar and read a sentence given just as an example of a grammatically correct sentence, say "John and Mary are going to school by bus". You do understand something, but this poor understanding of an isolated sentence does not give you the knowledge of any specific situation, because the tokens of the words simply inherit the semantic properties of their corresponding types. No new and richer semantic values are contextually derived and the sentence, consequently, is not clearly truth-evaluable. The understanding we have of the sentence certainly does not qualify as a case of spontaneous linguistic understanding. There are no intuitive truth conditions easily associated with the sentence. This is clearly not a serious and literal use of language. In semantics, since Frege, we all adopt the convention according to which the assessment of word meaning or a sentence meaning must proceed only on the supposition that the word or sentence is used seriously and literally, and, I would like to add, as part of a whole discourse. The interpretation of isolated sentences, normally, is not much more than a simple conjecture. Sometimes a sentence is used seriously and literally but the result is not very convincing. Take the sentence "There is life on Mars" (Dummett's example). If the understanding of a sentence is the knowledge of what is the case if it is true, what kind of knowledge do I have in such a case? ${ }^{18}$ The mere disquotational truth conditions for that sentence ("There is life on Mars" is true iff there is life on Mars) are totally uninformative. An exobiologist would certainly have a different understanding from the rest of English speakers. Are there occurrent understanding of standing meaning (for expressions-type)? Well, it happens each time you take a dictionary, but once again, it does not qualify as "spontaneous."

Standing meaning, by definition, must be relatively stable. Nonetheless, in natural languages, new uses of old words appear constant-

${ }^{18}$ For a different opinion, see Guy Longworth, "A Plea for Understanding", in Sawyer, S. (org.). New Waves in the Philosophy of Language. Aldershot: Ashgate, 2009, 138-163. As I said, cases of dispositional understanding of standing meaning of expression-type, certainly do not qualify as "spontaneous." Occurrent understanding of standing meaning emerge precisely when we do not understand the sentence used on a first reading; we have to stop, to think twice and to analyze its structure, check the lexical meaning, etc. 
ly. Take the word "here". "Wait for me here!" usually means "around here", not too far from the spot where you are right now, that is, where the utterance takes place. But nowadays, in many web pages, you find instructions saying: "Click here!", and to follow the command, you have to click on the very token of the word "here". This is a new (funny) use of the word, but no one ever had any problem in understanding it. Of course, the new use is related to the previous ones. Words in natural languages don't have by convention a limited number of uses or possible understandings or senses, and our linguistic policy does not determine in advance all the correct understandings of a term.

The occurrent understanding of utterances usually involved tokens produced in the context of utterance. We always produce these tokens in a specific situation. There is no such thing as coffee-in-general. The coffee we refer to is always fully determined, in a specific state (liquid, powder, or beans, etc.). Here the Austinian "demonstrative conventions" do the job, close the gap between the general and the specific, so to speak. A full semantic value for the token is derived in the context. Let me expand a little bit an interesting example given by J. M. Moravcsik. ${ }^{19}$ The word "walk" in the sentence "Jones had a walk" means different things if Jones is a healthy adult (she walked a few kilometers to stay in shape), or a toddler (she just gave her first steps in her whole life), or an elderly person in a hospital recovering from a serious disease (she walked painfully from his bed to the bathroom and back), or an athlete that undergone a surgery in his knee (she will be back to her team soon), or if Jones is always seen running (by contrast, exceptionally, she walked!). In natural languages, most of the time, a sentence is correctly understood when it is understood differently in different contexts. The upshot here is that the spontaneous linguistic understanding of utterances in natural languages is context-sensitive. ${ }^{20}$ And the first and immediate object of SLU is occasion meaning. It is useful to compare natural languages with the regimented languages

\footnotetext{
${ }^{19}$ See Julius Moravcsik (1998), Meaning, Creativity and the Partial Inscrutability of the Human Mind, Stanford, CSLI Publications, 1998.

${ }^{20}$ That understanding in natural language is context-sensitive is a thesis developed at length by Charles Travis in Unshadowed Thought, Cambridge (MA), Harvard University Press, 2000. See also Occasion-Sensitivity, Oxford, O.U.P., 2008.
} 
used in sciences, where a sentence is correctly understood when all the members of the scientific community understand it in the same way. For that reason, ordinary language is unsuited for systematic theorizing, or for scientific investigation and communication. The betterment of scientific communication is precisely what justifies regimentation. In a regimented or ideal language, special (technical, theoretical) words and concepts are introduced through definitions, and to define is precisely to delimitate conditions of application.

Occurrent understanding of sentences proceeds, first, by identifying the derived semantic value of the sub-sentencial parts of the sentence; this always precedes any act of predication. The next step consists in identifying the act of predication, I mean, what is predicated of what. This is the same as grasping a proposition. When the proposition grasped is a general one or a complex one, the identification of the first and second order predication is required; otherwise, the argument must also be identified in case of atomic proposition of the form $\mathrm{F}(\mathrm{a})$. In case of relations, especially asymmetric relations, the order of predication is of course important. Predication (or functional application) is the cement of propositions. The identification of various constituents and structural elements looks like a complex process, but this is just a product of analysis. When I see an old friend in a crowd, I do not pay any special attention to her eyebrows, chicks, hairs, the color of her eyes, etc. All this is familiar, and it is enough: I recognize her at once. The same holds for the spontaneous understanding of a sentence: if I know the words, and if the structure is not too complex, the proposition (or truth conditions) is grasped at once.

\section{Davidson's programme}

How do we have a so quick access to the content of an utterance when the token produced is the token of a sentence never heard before? Davidson's famous answer in 1967, before the qualifications added a few decades later, is that we must master somehow a compositional T-theory for the language we use. I see Davidson's conception as an attempt to describe the structure of our dispositional understanding. The T-theory is a theory of meaning (and understanding) for that language, and he argued that the format of such a theory is analogous 
to that of a formal system. First, we have a huge set of basic axioms specifying: a) the reference (meaning) of singular terms and b) compositional axioms for $\mathrm{n}$-ary predicates; second, the $\mathrm{T}$-sentences or theorems derived from the basic axioms and specifying the truth conditions for all the declarative sentences of the language. For instance, from the basic axioms I), II) and III) we can derive the following theorem or T-sentence:

IV. "Piaf is more famous than Ella" is true in English iff Piaf is more famous than Ella.

The theorem gives the truth conditions of the sentence-type mentioned, and explained how someone could understand that sentence on a first hearing.

There are a few wor thy problems to be mentioned here, especially for those who believe that knowledge of meaning (as specified by the axioms) is propositional knowledge, and those who "psychologized" Davidson's program in a cognitivist vein. 1) Truth conditions are not enough. As David Wiggins points out, when you try to pick up the right truth conditions of a sentence, say, "The Sun is behind cloud" (Wiggins' example), you must already have an understanding of the sentence in order to stop the list of many other things you might put on the right side of the corresponding T-sentence: "The Sun is behind cloud" is true in English iff the Sun is behind the cloud, and it is day time, the sun has risen, there are more people awake than asleep, etc. ${ }^{21}$ Furthermore, we understand illocutionary acts, and not only propositional clause, that is, a pair composed of a force and a propositional content, and any strategy to reduce the non-declarative to the declarative fragment of a natural language faces problems, especially in the case of expressive illocutionary acts. 2) An informative and non-circular specification of our knowledge of meaning expressed by the basic axioms has still to be produced; without a mode of presentation for the meaning, it seems that that cannot be done (this is

\footnotetext{
${ }^{21}$ See David Wiggins, "Meaning and Truth Conditions: From Frege's Grand Design to Davidson's", in B. Hale and C. Wright (Eds.), A Companion to the philosophy of Language, Oxford, Blackwell, 1997, p. 7. For similar remarks, see Scott Soames, What Is Meaning?, Princeton, Princeton University Press, 2010, chapter 3.
} 
Stephen Schiffer's mode of presentation problem). ${ }^{22}$ 3) As we have seen, a genuine propositional attitude is one that may serve many purposes and interact with other attitudes, as Gareth Evans rightly observed. This is clearly not the case of the knowledge of meaning expressed by the basic axioms. So it is at least doubtful that the basic axioms express genuine propositional knowledge. Almost 20 years after "Truth and Meaning" (1967), Davidson acknowledged the fact that the mastering of a T-theory is not enough for the understanding of an utterance and that its specification is always incomplete; an interpreter also needs a "passing theory". ${ }^{23}$

\section{Grice's program}

Grice's program focuses on occurrent understanding, that is, the understanding of utterances. The understanding of an utterance takes place when the hearer (the audience) recognizes the speaker's intention to cause a certain effect precisely by the recognition of that intention. The whole process of identification (recognition) of speaker's intention is regularly taken to be an inferential process. Grice's program faces problems too. 1) It does not accommodate very well the conventional aspects of communication and understanding; 2) It does not cope quite well with situations of counter-suggestion, confession and the anti-lying problem; ${ }^{24} 3$ ) Above all, it describes occurrent understanding mainly, if not exclusively, as an inferential process, so that there is no special difference between the understanding people have when they are speaking their mother tongue, and the

${ }^{22}$ See S. Schiffer, "The Mode of Presentation Problem”, in C. Anthony Anderson \& J. Owens (Eds.), Propositional Attitudes. The Role of Content in Logic, Language and Mind. Stanford, CSLI Publications, 1990, 249-268. Also, by the same author, "Knowledge of Meaning", in A. Barber (Ed.), Epistemology of Language, Oxford, O.U.P., 2003, 303-324.

${ }^{23}$ See D. Davidson, "A Nice Derangement of Epitaphs", in Lepore, E. (ed.), Truth and Interpretation: Perspective on the Philosophy of Donald Davidson, Oxford, Basil Blackwell, 1986.

${ }^{24}$ For an exposition of these problems, see Alex Barber, "Truth Conditions and Their Recognition”, in A. Barber (ed.), Epistemology of Language, op. cit, 367 395. 
kind of understanding a tourist has in a foreign country. Moreover, Grice's approach does not represent correctly the difference between the spontaneous linguistic understanding of ordinary people in ordinary circumstances, and the work done by hermeneutists. In other words, the Gricean program does not describe correctly occurrent, fluent, effortless understanding. For that reason, like Millikan, Recanati and others, I believe that understanding is better modeled as a kind of perception. ${ }^{25}$

\section{Perception and inference: a digression}

Sometimes the difference between perception and inference is not that clear and it seems that we have a mere difference of degree. You need to change your spectacles and go to consult your oculist. There are the letters projected on the wall; the first lines are easy, but the letters become smaller and smaller until you reach a point at which you are not anymore clearly perceiving, nor clearly inferring: Is it an "E" or an "F"?

In Leclerc (2009, 267-268) I mention

[...] a common distinction in the literature about two exclusive ways of representing communication and linguistic understanding: Firstly, there was the Code Model, sometimes called "the Expressive View", associated with Aristotle's De interpretatione and also to Port-Royal's Grammaire générale et raisonnée. This is certainly and by far the most enduring and influential conception of human communication in the whole history of philosophy. [...] The aim of any act of communication according to the Code Model is to share the same meanings. Secondly, there is the Inferential Model, sometimes called the "Convergence View," initiated half a century ago by Grice and developed also by Sperber \& Wilson. Davidson (1986) can also be seen as a proponent of this view. Here, the measure of success in human communication is the correct identification of speaker's meaning or intention through inferential processes, or to converge on the same meanings and to make the same inferences.

That Code-Inference opposition in the theory of communication and understanding is one more idealized opposition in which no one fits,

${ }^{25}$ Ruth Millikan, Varieties of Meaning. The 2002 Jean Nicod Lectures, Cambridge (MA), MIT Press, 2005; and Language: A Biological Model, Oxford, O.U.P., 2005. Also, François Recanati, “Does Linguistic Communication Rest on Inference?”, Mind \& Language, Vol. 17, numbers1 and 2 February/April, 105-126, 2002. 
one more procrustean bed. Both models are clearly incomplete. SLU must accommodate short and fast inferences. The stock example is the sentence "She took the keys and opened the door". We all understand (infer) that she opened the door with the keys, even if that component is not articulated in the sentence. A mother says to her son who is crying because of a very small cut on the tip of a finger: "Come on, you are not going to die" (Recanati's example); the intuitive proposition (or truth conditions) expressed here is that the boy in not going to die because of the small cut, and not, of course, that the boy is immortal. Many cases of contextual "enrichment" (Recanati's expression) are of this kind. The same holds for malapropisms. But not everything is inferred in linguistic understanding.

We have seen that there is an intuitive difference between knowing the content of an utterance, and understanding it. If a reliable translator tells me that an utterance in Russian means that Putin is wise, I am in a position to claim that I know the content of the utterance, but certainly not in a position to claim that I understand the utterance. SLU requires a strong degree of epistemic intimacy with the tokens produced in the context and the autonomous exercise of tacit semantic knowledge. To use a distinction made in Phenomenology and Gestalt psychology, in the perception of the tokens produced in the context of utterance, the subsidiary attention is directed to the sounds perceived (discourse recognition), but the focal attention is directed to the senses of the expressions, to the content of the utterance. In the same way, the pianist's focal attention is directed to the melody and the quality of her interpretation, not to the position of her fingers. Similarly, when we perceive objects around us, the focal attention is directed to the objects themselves and not to the shape, size or colors.

Grice's program is based on Mindreading (the identification of speaker's intention is certainly a form of Mindreading). But I don't think that Mindreading is best reconstructed as a kind of inference by analogy. It can be reconstructed as a kind of perception too. This is how I understand Alvin Goldman's simulation theory of Mindreading. Mindreading has been invoked a long time ago as a cornerstone of language use by Antoine Arnauld, classified as a proponent of the Code Model. Here is a quote from the Great Arnauld: 
One cannot reflect, however little, on the nature of human language without recognizing that it is entirely grounded on that imperfect penetration of the mind of the others. That is why, when speaking, there are many things we do not need to express. (My translation)

We wouldn't speak the way we do if our minds would be totally opaque to each other.

There is another analogy between perception and SLU. Perception is a dynamic process based on a retention-projection structure. We do not perceive all the sides of an object at once. On the basis of what we just perceived we project or anticipate the perception of the other sides. Sometimes we commit mistakes. We thought that we were seeing a house, but it is only a façade put there by the staff of a filmmaker. But perception is a self-correcting process. Misperception is corrected by perception. SLU is also a dynamic process. Conversations usually involve turn-taking and sequences of utterances. Rarely do we have to understand isolated utterances. The utterances we just understood determine what Grice called in his famous Principle of Cooperation "the accepted purpose or direction of the talk exchange in which you are engaged." ${ }^{26}$ They also help us to restrict the range of possible interpretations for the new utterances produced in the talk exchange and to project further possible developments in the conversation.

\section{Conclusion: plans, scripts and situations ${ }^{27}$}

The approach I am trying to develop is not new. It is a bottom-top approach in which it is semantics that must answer to pragmatics, as Brandom once put it. The approach is based on ideas that can be traced back to the works of Arnauld, Peirce, Wittgenstein, Austin and more recently Travis and Recanati. In Leclerc (2009, 271), I gave it the following wording:

\footnotetext{
${ }^{26}$ Paul Grice, "Logic and Conversation", in P. Grice, Studies in the Way of Words. Cambridge (MA), Harvard University Press, 1989, p. 26.

${ }^{27}$ Part of the material of this section has been published in Manuscrito, Vol. 32, $\mathrm{n}^{\mathrm{o}} 1$, jan-jun, 2009, Special Issue: Semantic Content and Communication. A. Leclerc, E. Perini-Santos \& M. Ruffino (eds.). See my "Meanings, Actions and Agreements", in that issue, 249-288.
} 
Actions and practices are the roots of linguistic understanding. In a pragmatic approach, we start with actions, of which speech acts are important sub-species, and actions are what we interpret. Actions are performed for different reasons, and are parts of bigger plans. Words and sentences are seen and understood as instruments used in the performance of actions. My suggestion is that we should consider plans or scripts and not only actions, as the unit of investigation. I also suggest that the expectations of agents (speakers-hearers), and the correct identification and understanding of these expectations, are especially important for the determination of the sense of the words used in an occasion. In other words: The root of any distinction in thought and in the sense of linguistic expressions is found in its sensible effects, in our practices, plans and activities. This principle I call the Principle of the Determination of Sense.

What makes this principle so important is the phenomenon of the plasticity or underdetermination of sense in ordinary language, the fact that different tokens of the same sentence-type may have different truth conditions in different contexts of use. On that score, Austin's theory of truth accommodates that phenomenon much better than Tarski's.

SLU presupposes a great dose of "worldliness and reasonableness", as Travis (2000) used to say. We share the same world, as Davidson pointed out. However, taken at its face value, that does not take us very far. The knowledge of the world is very different from one person to the next. And the world we live in - not the one described by physics - is forever changing. The same could be said of the knowledge of our language (as the norm of a community). We know that social class, education and learning, scientific discipline, influences from good or bad neighborhood, etc. may contribute to create discrepancies among the idiolects of the people living in the same community (What we call "ordinary language" itself is changing all the time, even if you define it as the degree zero of "regimentation”.)

But "our knowledge of the world" can be understood alternatively as something that comprehends, I still believe,

[...] all the knowhow, all the practices we learn just by growing up in a community, with almost everyone as a teacher, including social regularities like linguistic conventions, an especially important kind of social regularity. This is huge and widely shared among the members of the community. We do not agree or converge on meaning simply because we "grasp" somehow the same eternal "forms," but rather because we 
share a world in which we are integrated, and because we are worldly enough to see what to expect from each other. Our mutual linguistic understanding relies on that encyclopedic knowledge concerning how things are and how they are made, and on basic discriminatory capacities and abilities like mindreading and inferential ability. (Leclerc, 2009, 279).

For that reason, I do not believe that SLU correspond to a module of the mind. It does not satisfy two basic conditions for modularity: informational encapsulation, and domain specificity.

Now I want to suggest an idea that cannot be fully developed here. Consider for one moment the internal accusative of the verb "understanding". The list covers almost everything that is intelligible. We understand sentences, languages, cultures, books, face expressions, persons, attitudes, expectations, arithmetical series, problems, strategies, musical phrases, paintings, narratives and situations, physical systems, mechanisms, and certainly much more. My suggestion is that "linguistic understanding is only a part of it, and not an autonomous (modular) one. Linguistic understanding relies on more primitive forms of understanding, specially the understanding of situations." (Leclerc, 2009, 274). It is not easy to say exactly what a situation is. A sentence-type describes a generic situation that may be found (or not) in the world. But we saw that the tokens of declarative sentences are always produced in a very specific situation, where the demonstrative conventions anchor the constituents of the sentence to specific, concrete objects, historical facts, etc. As a first approximation, I would say that a specific situation involves essentially agents with their expectations and plans, and how things are and could be. In ordinary language, an understanding of the specific situation (including the identification of expectations, intentions and plans through mindreading) is usually decisive for a correct understanding of the token produced in the context. I think Austin's theory of truth captures very well that difference, with its two types of conventions (descriptive and demonstrative). Take a sentence (token) from the specific situation where it has been produced, and many possible different understandings immediately come to mind. For instance, Putnam's example, "there is a lot of coffee on the table", can be true in very different settings, where "the way things are" might differ drastically (if there is a big coffee pot on the table, or if there are 
bags of coffee beans on the table, or if someone spilt an entire coffee cup on the table, etc. We understand differently tokens of the same sentence because we have an understanding of the way things are in the specific situation we are in. A sentence taken from a specific context of use may serve different purposes from the one for which it has been uttered.

Now, consider the following sentences:

(a) You are very much Paris.

(b) Give peace a chance!

(c) Pride has a city!

(d) The Cardinal Mazarin has sent here his hemispheres.

(e) John speaks fluently English.

The first three are literal "nonsenses", but we do understand them easily. a) means that the addressee behaves very much like people do in Paris; b) means that we should try to create conditions for peace; c) that the people are proud of their city, and so are their servers in City Hall; d) is a malapropism. It really happened in Paris Parliament in the XVII ${ }^{\text {th }}$ century, but the deputy who uttered the sentence was immediately understood as saying: The Cardinal Mazarin has sent here his emissaries. e) is perceived as ungrammatical. We hear and understand easily a lot of ungrammatical sentences, especially from children. These cases are marginal, of course, but they reveal something interesting for my purpose. SLU is understanding of utterances, of actions performed for such and such a reason, and its first and primary object is occasion meaning. Occasion meaning is the result of a pre-propositional "modulation" (Recanati's expression) of standing meaning. The common use of language is a rulegoverned rational activity, and rationality is precisely an unlimited capacity to realize intentional adjustments in a huge diversity of context. We revise our beliefs and plans constantly in the light of new information and evidence. This is what we do when we speak, and we speak in order to be understood. When we understand enough of the situation we are in, including the expectations and plan of the speaker, the words we hear are taken to carry the occasion meaning that most relevantly may contribute to the success of speaker's actions and plans at the moment of the utterance. It is that understand- 
ing of the specific situation that enables us to understand easily and spontaneously ungrammatical sentences and malapropisms. If SLU were a kind of unconscious word processing mechanism, our ability to understand utterances involving deviant sentences would be seriously impaired.

André Leclerc

Federal University of Ceará-Fortaleza

\section{References}

Arnauld, Antoine \& Nicole, Pierre. 1669-1672. La Grande Perpétuité de la foi de l'Eglise catholique sur l'Eucharistie, [G.P.], publiée par l'Abbé M***, Paris : Imprimerie de Migne, chez l'éditeur rue d'Amboise, Hors la barrière d'Enfer,
1841.

Austin, John L. Truth. In Philosophical Papers. Oxford: Clarendon Press, 1979.

Barber, Alex (ed.), Epistemology of Language, Oxford: O.U.P., 2003.

Barber, Alex. Truth Conditions and their Recognition. In Epistemology of language, 367-395.

Burge, Tyler. Comprehension and Interpretation. In The Philosophy of Donald Davidson, ed. by L.E. Hahn. Chicago and La Salle: Open Court, 1999.

Davidson, Donald. A Nice Derangement of Epitaphs. In Truth and Interpretation: Perspective on the Philosophy of Donald Davidson, ed. by E. Lepore. Oxford: Basil Blackwell, 1986. (Also in D. Davidson, Truth, Language and History. Oxford: Clarendon Press, 2005, 89-108.)

Davidson, Donald. The Social Aspects of Language. In Truth, Language and History, 109-128. First published in B. McGuinness \& G. Oliveri (eds.) The Philosophy of Michael Dummett, Dordrecht, Kluwer Academic Press, 1994.

Davidson, Donald. 1967. Truth and Meaning. Synthese 17

Dummett, Michael. 1993. Origins of Analytical Philosophy. Cambridge (MA): Harvard University Press.

Evans, Gareth. Semantic Theory and Tacit Knowledge. In Wittgenstein: To Follow a Rule, ed. by S. Holtzmann \& C. Leich. London: Routledge, 1981. (Also in G. Evans, Collected Papers. Oxford, Clarendon Press, 1985, 322-342.)

Grice, H. Paul. 1975. Logic and Conversation. In Studies in the Way of Words. Cambridge (MA): Harvard University Press, 1989.

Lakoff, George. 2004. Don't Think of an Elephant! White River Junction (Vermont): Chelsea Green Publishing.

Leclerc, André. Communication, Linguistic Understanding and Minimal Rationality in the Tradition of Universal Grammar. In Logic, Thought and Action, ed. by D. Vanderveken. Dordrecht: Springer, 2005, 133-150.

Leclerc, André. Meanings, Actions and Agreements. Manuscrito, Vol. 32, nº1, jan-jun, 2009, Special Issue: Semantic Content and Communication, ed. by A. Leclerc, E. Perini-Santos \& M. Ruffino 249-288.

Longworth, Guy. A Plea for Understanding. In New Waves in the Philosophy of Language, ed. by S. Sawyer. Aldershot: Ashgate, 2009.

Millikan, Ruth. 2004. Varieties of Meaning. The 2002 Jean Nicod Lectures, Cambridge (MA): The MIT Press.

Millikan, Ruth. 2005. Language: A Biological Model, Oxford: O.U.P.

Moravcsik, Julius. 1998. Meaning, Creativity and the Partial Inscrutability of the Hu- 
man Mind. Stanford: CSLI Publications.

Pettit, Dean. 2002. Why Knowledge is Unnecessary for Understanding Language. Mind, Vol. 111, n. 443, July 2002

Polanyi, M. 1966/2009. The Tacit Dimension. Chicago: The University of Chicago Press.

Recanati, François. Does Linguistic Communication Rest on Inference? Mind \& Language, Vol. 17, numbers1 and 2 February/April, 105-126, 2002.

Recanati, François. 2004. Literal Meaning, Cambridge, C.U.P.

Recanati, François. 2010. Truth Conditional Pragmatics, Oxford, O.U.P.

Schiffer, Stephen. The Mode of Presentation Problem. In Propositional Attitudes. The Role of Content in Logic, Language and Mind, ed. by C. Anthony Anderson \& J. Owens. Stanford: CSLI Publications, 1990, 249-268.

Schiffer, Stephen. Knowledge of Meaning. In Epistemology of Language, ed. by A. Barber. Oxford: O.U.P., 2003, 303-324.

Soames, Scott. 2010. What Is Meaning? Princeton: Princeton University Press.

Travis, Charles. 2000. Unshadowed Thought. Cambridge (MA): Harvard University Press.

Travis, Charles. 2008. Occasion-Sensitivity, Oxford, O.U.P.

Wiggins, David. Meaning and Truth Conditions: From Frege's Grand Design to Davidson's. In A Companion to the Philosophy of Language, ed. by B. Hale and C. Wright. Oxford: Blackwell, 1997.

Wittgenstein, Ludwig. The Big Typescript. Oxford: Blackwell, 2005.

Wright, Crispin. Theories of Meaning and Speakers' Knowledge. In Realism, Meaning and Truth. Oxford: Blackwell, 1993, 204-238. 